\title{
Comparison of a Vessel Sealing System with a Conventional Technique in Hemorrhoidectomy
}

\author{
Serkan Teksöz, Erman Aytaç, Nihat Yavuz, Osman Baran Tortum, Murat Özcan, Sabri Ergüney, Yusuf Bükey \\ Department of General Surgery, Cerrahpaşa Medical Faculty, İstanbul University, İstanbul, Turkey
}

\begin{abstract}
Objective: Milligan-Morgan, Park and Ferguson hemorrhoidectomy procedures are the ones most frequently used for the surgical treatment of hemorrhoidal disease. Attempts to modify these conventional approaches are made by using different techniques or tools to decrease blood loss, and reduce operating time and postoperative analgesic requirement. In this prospective randomized trial, the conventional Ferguson hemorrhoidectomy method is compared with the LigaSure ${ }^{\circledR}$ hemorrhoidectomy according to various criteria.
\end{abstract}

Material and Methods: Forty patients who had grade 3-4 hemorrhoidal disease were randomly divided into two equal groups: the Ferguson Hemorrhoidectomy $(n=20)$ and the LigaSure ${ }^{\circledR}$ hemorrhoidectomy $(n=20)$. Operating time, demographic data, intraoperative and postoperative complications, postoperative pain, return of bowel movements and postoperative hospital stay were evaluated. The visual analogue score was used for the evaluation of pain on the first postoperative day. The patients have been followed up for at least 19 months.

Results: The pain score, blood loss and operating time were significantly reduced in the LigaSure ${ }^{\circledR}$ hemorrhoidectomy group.

Conclusion: LigaSure ${ }^{\circledR}$ hemorrhoidectomy is safe and feasible for the surgeon, and more comfortable than classical surgery for the patient.

Key Words: LigaSure ${ }^{\circledR}$, Ferguson hemorrhoidectomy, closed hemorrhoidectomy, follow up, randomized prospective study

Received: 21.07 .2009

Accepted: 01.04 .2010

\section{Introduction}

Hemorrhoidal disease presenting with minor symptoms could be managed with medical therapy. However, the ideal therapy for grade 3 and grade 4 hemorrhoidal disease is surgery. Milligan-Morgan, Park and Ferguson hemorrhoidectomy methods are the most preferred techniques (1). Lynn Ferguson reported the technique bearing his name in $1959(2,3)$. Successful results of Ferguson's technique showed that a closed wound could heal as well as open wounds after hemorrhoidectomy. Longo and Pescatori $(4,5)$ used a circular stapler for the treatment of prolapsing hemorrhoids. This technique combines hemorrhoidectomy and anopexy. Longo's hemorrhoidectomy reduces post operative pain and hospital stay $(4,5)$.

Use of the new developed devices in performing the classical surgical techniques is a new field of surgical research with numerous advantages such as: shorter hospital stay, reduced operation time, less blood loss, reduced complication rate and pain $(6,7)$. LigaSure ${ }^{\circledR}$ is a practical and safe thermal vessel sealing device. Various beneficial effects of the thermal sealing systems had been documented (8). In this prospective randomized clinical study, the conventional Ferguson hemorrhoidectomy was compared with the LigaSure ${ }^{\circledR}$ hemorrhoidectomy.

\section{Patients and Methods}

This study was performed after the approval of the Ethics Committee of the Human Studies Review Board of Istanbul University Cerrahpaşa Medical Faculty. The patients were randomly divided into two equal groups before surgery with a random number generator. Ferguson's hemorrhoidectomy or Liga Sure ${ }^{\circledR}$ hemorrhoidectomy were performed on the forty patients who had grade 3 or grade 4 hemorrhoidal disease in the Division of Gastrointestinal Surgery, Department of General Surgery, Cerrahpaşa Medical Faculty between December 2005-October 2007. The patients had no accompanying disease other than hemorrhoidal disease. Coexisting anorectal disease, previous anorectal operation, thrombosed hemorrhoids, hematologic pathology, inflammatory bowel disease, and unwillingness of the patient were the exclusion criterias.

The demographic data, duration of surgery, blood loss during surgery, intraoperative and post operative complications, postoperative pain, the initiation of bowel movement and postoperative hospital stay were evaluated. The blood loss was calculated by measuring the blood volume collected in the receptacle of the suction device and by substracting the dry weight of the gauzes from their wet weights. The postoperative pain was evaluated with the visual analogue score (VAS) the day after surgery. The 
visual analogue pain evaluation scale was presented and explained to the patients before surgery and their understanding was confirmed. The patients unable to ascertain the scales were excluded from the study. The details of the study were explained to all the patients included in the study. The patients signed informed consent forms. No patient dropped out of the study during the study. Surgery was performed by the same team.

The patients were placed in the lithotomy position and a Ferguson retractor was used to expose the hemorrhoids. In LigaSure ${ }^{\circledR}$ hemorrhoidectomy, the hemorrhoid bundle was grasped and retracted. The device (LigaSure ${ }^{T M}$ Max system) was applied 1-2 $\mathrm{mm}$ away from the skin-mucosa junction. The hemorrhoid bundle resection was started at the junction of the hemorrhoid and the flat perianal skin up to the base of the pedicle without performing submucosal dissection. An antibiotic ointment soaked gauze was inserted into the anal canal after the surgery. All procedures were performed with the LigaSure vessel sealing device (LigaSure ${ }^{\mathrm{TM}}$ Max system). Conventional Ferguson hemorrhoidectomy was performed in accordance with the standard technique (3). Three hemorrhoid piles were excised for each patient in both groups. All operations were performed under general anesthesia. Standard postoperative analgesic regimen was given to the patients.

After discharging the patients from the hospital they were called for control on postoperative day seven and four weeks after surgery during the early postoperative period. To analyse the long term outcomes, the patients were called to the out patient clinic every six months. No patients dropped out of the study during the follow up period. The follow up data was collected from the outpatient clinic by one of the authors (ST).

Power analysis was done before the study to determine the minimum patient number. The sample size, $n=16$, in each group were required based on following four assumptions: a) significant rise $(\geq 10 \%)$ in pain degree in operative time; b) a $\alpha$ error of 0.05 a $\beta$ of $80 \%$. All data were expressed as mean \pm standard deviation. The data were compared using Student's t test. SPSS 10.0 (SPSS: Statistical Package for Social Sciences) was used for assessing the significance of differences between groups. $p<0.05$ was considered significant.

\section{Results}

The follow up time was $31.7 \pm 6.55$ months for the Ferguson's hemorrhoidectomy group and 30.2 \pm 6.51 months for the Liga Sure ${ }^{\circledR}$ hemorrhoidectomy group. The mean age of the patients who underwent Ferguson Hemorrhoidectomy (twelve men, eight women) was 37.7 \pm 15.5 . The mean age of the patients who underwent LigaSure ${ }^{\circledR}$ Hemorrhoidectomy (ten men, ten women) was $50.75 \pm 18.5$. There was no significant difference between groups for the follow up time, gender, grade of hemorrhoids and mean ages (Table 1).

There was no intraoperative complication in either group. One patient of the LigaSure ${ }^{\circledR}$ hemorrhoidectomy group complained of perianal pain for ten days after surgery. However, the pain degree at the first postoperative day, the blood loss during the surgery, and the duration of surgery of the LigaSure ${ }^{\circledR}$ hemorrhoidectomy group was significantly lower than in the Ferguson Hemorrhoidectomy group $(p<0.05, p<0.001$, $p<0.001$ respectively) (Table 2 ). Urinary retention was observed in two patients (10\%) who underwent Ferguson Hemorrhoidectomy. Postoperative bleeding had occurred 2 hours after surgery in a patient $(5 \%)$ in the Ferguson Hemorrhoidectomy group and it was managed with adrenaline soaked surgical gauze application. However, no complication was seen in two groups in the following months. The complications are summarized in Table 3.

\section{Discussion}

The complication rate after hemorrhoidectomy is usually proportional to the grade of the disease and invasive-

Table 1. Demographic data of the patients and the follow up times

\begin{tabular}{|lcc|}
\hline & $\begin{array}{c}\text { Ferguson } \\
\text { Hemorrhoidectomy } \\
(\mathbf{n}=\mathbf{2 0})\end{array}$ & $\begin{array}{c}\text { LigaSure } \\
\text { Hemorrhoidectomy } \\
(\mathbf{n}=20)\end{array}$ \\
\hline Age (year) & $37.7 \pm 15.5$ & $50.75 \pm 18.5$ \\
Gender & $8 \mathrm{~F}, 12 \mathrm{M}$ & $10 \mathrm{~F}, 10 \mathrm{M}$ \\
Follow up time & $31.7 \pm 6.55$ & $30.2 \pm 6.51$ \\
(month) & & \\
\hline M: male; F: female & & \\
\hline
\end{tabular}

Table 2. Quantitative surgery parameters in study groups

\begin{tabular}{|c|c|c|}
\hline & $\begin{array}{c}\text { Ferguson } \\
\text { Hemorrhoidectomy } \\
(n=20)\end{array}$ & $\begin{array}{l}\text { LigaSure } \\
\text { Hemorrhoidectomy } \\
(n=20)\end{array}$ \\
\hline $\begin{array}{l}\text { Duration of } \\
\text { surgery (min) }\end{array}$ & $32.22 \pm 9.72$ & $\begin{array}{c}10.75 \pm 6.71 * \\
(p<0.001)\end{array}$ \\
\hline $\begin{array}{l}\text { Volume of bleeding } \\
\text { during surgery (cc) }\end{array}$ & $25.56 \pm 11.30$ & $\begin{array}{c}1.75 \pm 3.62^{\star} \\
(p<0.001)\end{array}$ \\
\hline $\begin{array}{l}\text { Initiation of bowel } \\
\text { movement post } \\
\text { operatively (day) }\end{array}$ & 1 & 1 \\
\hline $\begin{array}{l}\text { Postoperative } \\
\text { hospital stay (day) }\end{array}$ & $1.1 \pm 0.33$ & 1 \\
\hline $\begin{array}{l}\text { Pain degree on } \\
\text { postoperative } \\
\text { day one }\end{array}$ & $6.56 \pm 2.24$ & $\begin{array}{c}3.25 \pm 3.06 * \\
(p<0.05)\end{array}$ \\
\hline
\end{tabular}

Table 3. Postoperative complications are summarized below in the table

\begin{tabular}{|lcc|}
\hline Complications & $\begin{array}{c}\text { Ferguson } \\
\text { Hemorrhoidectomy } \\
(\mathbf{n}=20)\end{array}$ & $\begin{array}{c}\text { LigaSure } \\
\text { Hemorrhoidectomy } \\
(\mathbf{n}=20)\end{array}$ \\
\hline Prolonged pain & $1(5 \%)$ & $1(5 \%)$ \\
$\begin{array}{l}\text { Urinary retention } \\
\text { Postoperative }\end{array}$ & $2(10 \%)$ & - \\
bleeding & $1(5 \%)$ & - \\
\hline
\end{tabular}




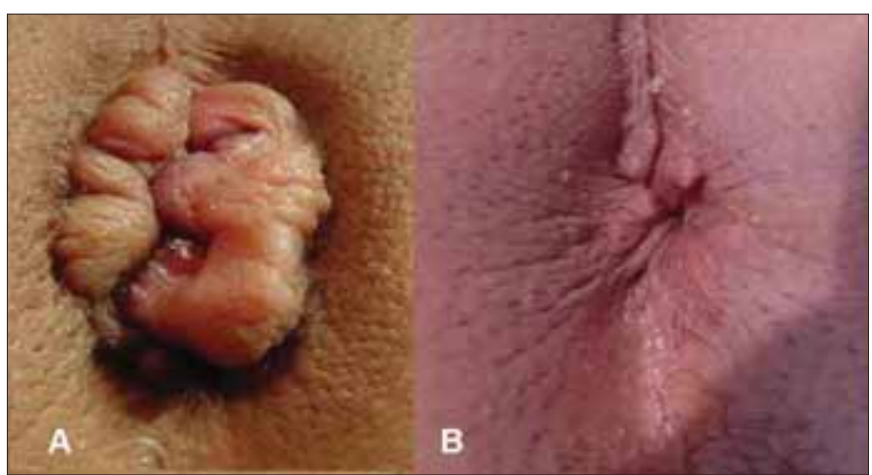

Figure 1. The preoperative (A) and the postoperative (B) (six days after surgery) appearance of the perianal area of a patient who underwent LigaSure ${ }^{\circledR}$ hemorrhoidectomy

ness of surgery. Pain, bleeding, urinary retention and infection are the major complications after hemorrhoidectomy. Patients undergoing hemorrhoidectomy usually complain of postoperative pain. Anodermal and perianal skin injury could cause postoperative pain after hemorrhoidectomy. Increased pain causes urinary retention in the early postoperative period (1). The rate of urinary retention, which is the most common complication after hemorrhoidectomy, is between $10 \%$ and $32 \%$ (9). The thermal vessel sealing systems could cause post operative pain via thermal injury. Thermal injury of vessel sealing systems to adjacent tissue was documented (1). Jayne et al. (10) reported that different types of vessel sealing systems alter analgesic use after surgery. It is of note that LigaSure ${ }^{\circledR}$ hemorrhoidectomy caused no urinary retention, which was seen in the Ferguson hemorrhoidectomy group. Tan et al. (11) reported that Liga Sure Hemorrhoidectomy reduced urinary retention rate significantly. However, in another study, it was shown that the rate of urinary retention, constipation, anal fissure and stenosis following the Ligasure procedure was no different from conventional hemorrhoidectomy (12). There is as yet no a consensus about the subject.

Application of thermal vessel sealing systems has provided many advantages to surgical procedure such as reduced operation time, reduced peroperative blood loss and simplified dissection $(6,8,13)$. Less thermal injury results in less postoperative pain (1). LigaSure ${ }^{\circledast}$ causes less thermal injury than monopolar or bipolar electrocauteries (10). In our study LigaSure ${ }^{\circledR}$ hemorrhoidectomy significantly decreased the pain of first postoperative day compared to Ferguson's hemorrhoidectomy. However, a patient complained of prolonged pain for ten days after LigaSure ${ }^{\circledR}$ hemorrhoidectomy.

Franklin et al. (8) reported that LigaSure ${ }^{\circledR}$ hemorrhoidectomy reduces postoperative pain and the time to first defecation. However, in the present study, the time of return of peristalsis was not different between the two groups Application of LigaSure ${ }^{\circledR}$ for hemorrhoidectomy reduced operating time and operative blood loss. LigaSure ${ }^{\circledR}$ use for hemorrhoidectomy provides immediate hemostasis and there is no need to suture the pedicle of hemorrhoids. Bleeding may be controlled by epinephrine injection, topical adrenaline application or suturing (1). Additionally, there was no postoperative bleeding in the LigaSure ${ }^{\circledR}$ hemorrhoidectomy group. It has been suggested that LigaSure ${ }^{\circledR}$ could simplify the hemorrhoidectomy procedure. LigaSure ${ }^{\circledR}$ hemorrhoidectomy could support wound healing process by reducing tissue trauma, tissue necrosis and tissue edema (Figure 1). Using thermal vessel sealing systems could increase the cost of the procedure (1). However, the advantages of the device such as less pain, faster recovery and beneficial effects on life quality should be borne in mind (1).

While our study was being carried out Wang et al. (14) published their randomized study on LigaSure with submucosal dissection versus Ferguson's hemorrhoidectomy for prolapsed hemorrhoids. They had 84 patients but follow up time was 8 weeks. They reported the short-term benefits of LigaSure ${ }^{\circledR}$ hemorrhoidectomy such as reduced intraoperative blood loss, shorter operating time, early resumption of work or normal activity and less postoperative pain, but they had no comment on the long-term results of this procedure. Their late complication rate was $6 \%$ after hemorrhoidectomy. Common late complications are anal fissure, anal stenosis, fecal incontinence or mucosal prolapse $(1,14)$. Our short term results were in accordance with the study of Wang. However, we observed no difference between groups for postoperative hospital stay and during the prolonged follow up period. Additionally, we encountered no anal stenosis, anal fissure or fecal incontinence in the two groups. Patient selection could be a key factor that could affect postoperative outcomes. Excluding the risky and chronic disease patients can reduce complication rates.

Scalding, skin bridges and anal stenosis are the main problems after hemorrhoidectomy with thermal vessel sealing devices. Scalding could be a predisposing factor for skin bridges after hemorrhoidectomy (7). Chung and $\mathrm{Wu}^{1}$ recommended a skin incision before hemorrhoidectomy and retraction of the hemorrhoid piles to reduce the harmful effects of thermal injury. We applied the Liga Sure 1-2 mm away from the skin-mucosa interface by retracting them. We did not incise the skin before hemorrhoidectomy. Our patients did not complain of scalding after surgery and we did not observe any skin burn on the perianal area. The learning curve could possibly be another important factor that affects the post operative complications.

In this study we have only compared a conventional technique with another one, which used a vessel sealing system with limited number of patients. Furthermore, additional evaluation parameters such as cost effectiveness could be added. This study forms a sound basis for further comparative studies of higher power between other vessel sealing systems and conventional surgical procedures. In this study, we observed some beneficial effects of LigaSure ${ }^{\circledR}$ hemorrhoidectomy, such as less blood loss, less postoperative pain and reduced operation time. LigaSure ${ }^{\circledR}$ hemorrhoidectomy is a feasible and time saving technique for the surgeon and a comfortable procedure for the patient.

\section{Conflict of Interest}

No conflict of interest was declared by the authors. 


\section{References}

1. Chung $\mathrm{Y}, \mathrm{Wu} \mathrm{H}$. Clinical experience of sutureless closed hemorrhoidectomy with LigaSure ${ }^{\circledR}$.Dis Colon Rectum 2003;46:87-92.

2. Smith LE. Hemorrhoidectomy with Lasers and Other Contemporary Modalities. Surg Clin N Am 1992;72:665-79.

3. Ellesmore S, Windsor ACJ. In: Mann CV (ed.) Springer: Verlag London; 2002;1-4.

4. Zacharakis E, Pramateftakis MG, Kanellos D, Kanellos I, Betsis D. Long-term results after transanal stapled excision of rectal internal mucosal prolapse. Tech Coloproctol 2007;11:67-8.

5. Longo A. Treatment of Hemorrhoidal? Disease by Reduction of Mucosa and Haemorrhoidal Prolapse with a Circular Suturing Device:New Procedure.In: Sixth World Congress of Endoscopic Surgery; Jun 3-6; Rome, Italy. 1998;777-90.

6. Armstrong DN, Frankum C, Schertzer ME, Ambroze WL, Orangio GR. Harmonic Scalpel hemorrhoidectomy:five hundred consecutive cases. Dis Colon Rectum 2002;45:354-9.

7. Ramcharan KS,Hunt TM. Anal stenosis after LigaSure hemorrhoidectomy. Dis Colon Rectum 2005;48:1670-1.

8. Franklin EJ, Seetharam S, Lowney J, Horgan PG. Randomized clinical trial of LigaSure vs.conventional diathermy in hemorrhoidectomy. Dis Colon Rectum 2003;46:1380-3.
9. Nivatvongs S. Hemorrhoids. Principles and Practice of Surgery of Colon, Rectum and Anus (Third edition). Gordon $\mathrm{PH}$, Nivatvongs S (eds).Informa Healthcare USA, New York 2007;143-66.

10. Jayne DG, Botterill I, Ambrose NS, Brennan TG, Guillou PJ, O'Riordain DS. Randomized clinical trial of LigaSure versus conventional diathermy for-day case hemorrhoidectomy. Br J Surg 2002;89:428-32.

11. Tan EK, Cornish J, Darzi AW, Papagrigoriadis S, Tekkis PP. Metaanalysis of short-term outcomes of randomized controlled trials of LigaSure vs conventional hemorrhoidectomy. Arch Surg 2007;142:1209-18.

12. Nienhuijs $S$, de Hingh I. Conventional versus LigaSure hemorrhoidectomy for patients with symptomatic Hemorrhoids.Cochrane Database Syst Rev 2009;21:CD006761.

13. Tan JJY, Seow-Choen F. Prospective, randomized trial comparing diathermy and Harmonic Scalpel hemorrhoidectomy. Dis Colon Rectum 2001;44:677-9.

14. Wang JY, Lu CY, Tsai HL, Chen FM, Huang CJ, Huang YS, et al. Randomized controlled trial of LigaSure with submucosal dissection versus Ferguson hemorrhoidectomy for prolapsed hemorrhoids. World J Surg 2006;30:462-6. 